\title{
Design of a potato stubble cutting machine for side delivery
}

\author{
Peng Tang, Shiyi Ren, Jikui A, Zheng Liu and Xiaorong Lv* \\ College of Mechanical and Electrical Engineering, Sichuan Agricultural University, Ya'an, China
}

\begin{abstract}
In order to solve the problem that the traditional stubble cutting machine of potato is not complete, which the chopped stalks cannot be collected and utilized, a side delivering potato stubble cutting mechanism was designed in this paper. The characteristic is that the cutting, clamping and delivering of potato plant stalks completed by the cooperation of the reel and the triangle-clamping chain, and the strip is laid on the right side of the machine. The machine can manually adjust the height of the cutting table, easy to operate, installed in the front of the tractor.
\end{abstract}

Keywords: Potato stubble; Cutting machine; Side delivery; Preprocessing before harvest.

\section{Introduction}

Because of its high grain and feed nutrition, potato planting area and yield in China increased rapidly with the help of consumption demand and the support of national industry $[1,2]$, and became the fourth largest food crop after rice, wheat and corn. The mechanized production of potato planting can greatly improve the economic benefit of farmers and reduce the labour intensity. However, China's potato harvesting machinery developed later than foreign countries. As a result of different terrain and different regions in China, potato planting mode and mechanization development are dissimilar [3]. Large amount of work, seasonality and labour intensity are characteristic for potato sowing and harvesting [4]. The potato needs to be stubble before harvest, and the harvest after stubble cutting can avoid the winding of weeds, so as to improve the working fluency and efficiency of potato harvester [5]. At the same time, stubble can promote the aging of potato skin and improve the ability of anti-scratch to reduce the skin damage rate in harvest process and transportation and ensure the quality [6]. At present, the potato stubble cutting machine in our country is mainly a swing blade structure. In the high-speed operation of the swing blade, negative pressure is formed in the shell of the machine tool, so that the broken stalks are spread to the ground [7]. However, the stalks and leaves of potato are rich in nutrition and also contain many kinds of bioactive substances, which can be used not only for feeding, but also as raw materials for medicine and chemical industries in effect of its high utilization value [8]. In the traditional machine, only the potato stalks are broken and returned to the field, which cannot be further recycled. At the that time, under the condition that the ground is uneven, the swing blade is easy to hit the potato and cause damage to it [9]. In order to

*Corresponding author: 1xrxj2008@163.com 
solve the shortcomings of the traditional machine, a side delivery potato stubble cutting machine is designed in this paper for the purpose of realizing collection and utilization of stalks in the process of potato stubble cutting efficiently and conveniently.

\section{Overall structural design}

The structure of the side delivering potato stubble cutting device studied in this paper is shown in figure 1 . The potato stubble cutting device is mainly composed of a guiding mechanism, a delivering and cutting mechanism, walking wheels regulating mechanism, a suspension frame and an airframe. The potato stubble cutting device adopts three-point front suspension in the tractor, the engine distributes the power through the gearbox to drive the stubble cutting machine, the power passes through the transmission chain to the left and right rotating shaft, the middle transmission shaft, drives the wheel and the cutter to rotate, completes the clamping, cutting and delivering operation. The supporting shaft of the depth limiting wheel is consolidated between the supporting shaft and the frame. The supporting shaft is a spiral burr rod structure. The spiral burr rod can be manually rotated to adjust the height of the supporting shaft of the depth limiting wheel and to adjust the requirements of different stubble cutting.

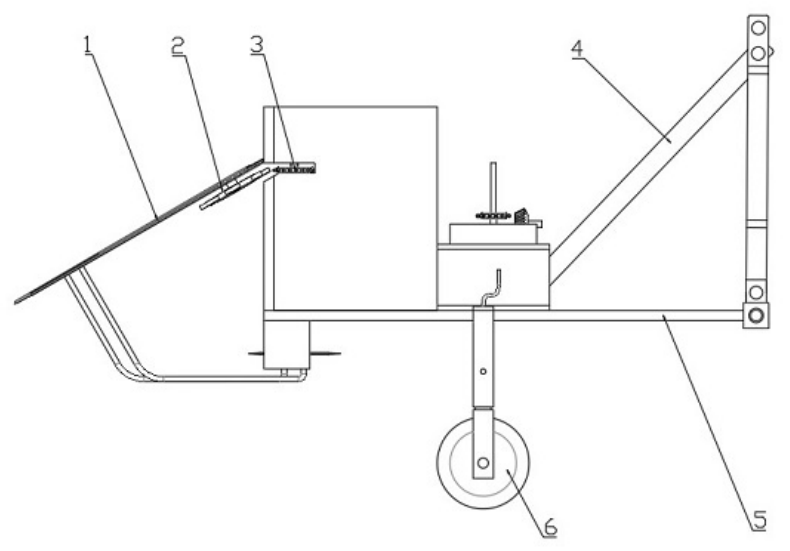

Fig. 1. General Structure Design of Potato stubble cutting machine.

1 guide sheet 2 reel 3 delivering cutting mechanism 4 suspension frame 5 airframe 6 walking wheels

Working principle: The operator can adjust the support height of the walking wheel according to the height of potato stalks. When the stubble height needs to be adjusted, the bolt is loosened first, then turn around the rocker on the walking wheels 6 to adjust the appropriate stubble height, and finally the bolt is consolidated. The realizable stubble heights are $100 \mathrm{~mm}, 80 \mathrm{~mm}$ and $60 \mathrm{~mm}$.

After the preparation work is completed, the tractor is started, and the engine power is transported to the stubble cutting mechanism through the gearbox. After the normal operation of the machine, the operator can start the stubble cutting operation at a certain speed. After the operation is completed, then the stalks will be manual collected and processed. 


\subsection{Design of the guiding mechanism}

In this paper, the guiding mechanism of potato stubble cutting mechanism needs to raise and introduce into stalks, and its design is shown in figure 2. Guide mechanism is composed of guide sheet, three small shafts, reel, support sheet and three guide support rods, in which the front section of guide sheet are lower than the back section of it, easy to guide, and the leak-proof guide sheet is close to the front section of the airframe, set at left side of the machine to prevent stalks from leaking out from this side.

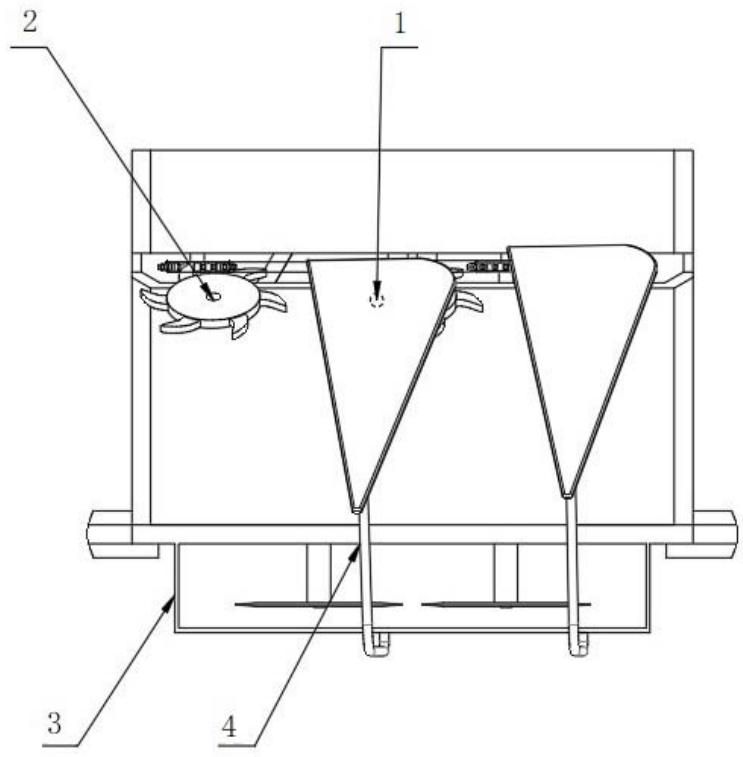

Fig. 2. Layout Diagram of the Guided Plate.

1 guide sheet small shaft hole 2 reel 3 support sheet 4 guide support rods

Working principle: As the machine begins to operate, the tractor moves forward and pushes the side delivery potato stubble cutting machine. In the process of moving through the guide mechanism, the potato stalks can support the falling stalks because of the height difference. On the other hand, the potato stalks are divided into two rows and sent to the effective cutting part of the disc blade. The guide sheet and the leak-proof guide sheet firstly contact the potato stalks and the field weed. At the same time, with the advance of the machine, the stalks and grass are gradually grabbed up, and the stalks and grass are firmly grasped by the meshing of the triangular delivery chain.

\subsection{Design of delivery or Cutting Mechanism}

The delivery and cutting mechanism mainly cut off the stalks from the guiding part, and then was arranged to the right side by the reel and the clamping chain, and its structure is shown in figure 3 . The conveying and cutting mechanism are mainly composed of delivery chain, transmission chain and transmission shaft. The power is driven by the gearbox through the left drive shaft. The drive chain rotates to drive the disc blade below the drive shaft to cut. The disc blade has a certain inclination angle and a triangular sawtooth at the edge. The drive chain rotates to drive the middle drive shaft, and then drives the disc knife under the middle drive shaft to cut. 


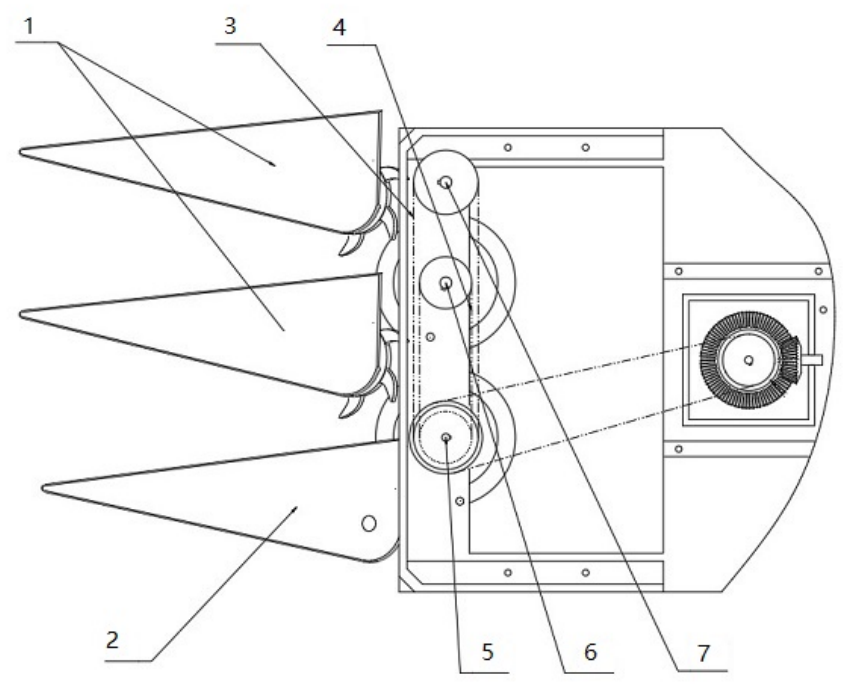

Fig. 3. Design of delivery or Cutting Mechanism.

1 Guide sheet 2 leak-proof guide sheet 3 delivery chain 4 transmission chain 5 left drive shaft 6 intermediate drive shaft 7 right drive shaft

Working principle: During the operation, the rotary disc blade is continuously transmitted by the drive shaft to provide power. The disc blades of the delivery cutting mechanism will cut the stalks and grass according to the stubble's height. The finished stalks will be squeezed to one side of the ridge.

\section{Discussion and conclusion}

\subsection{Discussion}

At present, the development direction of stubble cutting machine in China is mainly to improve the applicability and specificity of potato stubble treatment machinery, and to meet the needs of machinery [10]. The potato stubble cutting machine designed in this study has the advantages of simple structure, hanging the front of the tractor, and can be used to make grass feeding in animal husbandry after collecting potato stubbles, so as to improve the economic benefits of farmers. However, at present, the mechanism designed in this paper is still short of simulation and practical field test, only the structure design of the whole machine has been completed, the simulation of the 3D model and the trial production of the prototype have not been carried out. Finally, the actual harvest test is carried out to verify the expected effect of the design, and then compared and optimized.

\subsection{Conclusion}

1. The guide sheet and leak-proof guide sheet of this design have a certain angle to the ground and are inclined, and their shape is "V" structure, the front section is lower than the back section, so that the potato stalks can be divided into two rows in the process of side delivery of potato stubble cutting machine, and can support the stalks and facilitate the cutting of potato stalks; 
2. After cutting potato stalks, the design can transport between guide sheet and baffle in the effect of delivery chain and reel. The delivery chain which is arranged at $2 / 3$ height from the cutting site, can realize the smooth transportation of stalks and solve the problem of waste after the working of traditional stubble cutting machine.

The removal of potato stubble is the pre-treatment of potato harvest, which plays an important role in potato harvest quality. The design of a simple potato stubble cutting machine can improve our working efficiency and quality. It can become a good helper for farmers. In the future, the development of relevant practical agricultural machinery will contribute to the agricultural development of our country.

\section{Acknowledgements}

The study was supported by the National Key Research and Development Program, Intelligent Agricultural Machinery Equipment, (2018YFD0701100-03).

Corresponding Author: Xiaorong Lv (1972-), female, professor. Research field: Modern Agricultural Equipment Measurement and Control.

\section{References}

1. J. C. Guan, H.L. Cai. Characteristics and Causes of Potato Production Pattern Change in China [J]. Chinese Journal of Agricultural Resources and Regional Planning, 40(03):92-100, (2019).

2. H.M. Zhuo, S.Z. Fu, et al. Analyses and suggestions on current situation of potato industry standards in China[J]. Journal of Anhui Agricultural Sciences, 47(21):248250+270, (2019).

3. Z. Li, Q. Chang, J. Z. Liu, et al. Development Status and Trend of Potato Harvesting Machinery at Home and abroad [J]. Modern Manufacturing Technology and Equipment, 56(09):207-208, (2020).

4. Q. Feng. A Practice and Reflections on Promoting Mechanized Potato Planting Technology in Hilly and Mountain Areas [J]. Farm Machinery, (08):92-94, (2017).

5. Z. C. Wei, X. Q. Li, Yufan Zhang, et al. Advances in Technology and Equipment of Mechanized Potato Production [J]. Journal of Agricultural Mechanization Research, 39(09):1-6, (2017).

6. J.Q. Lv, Q.Q. Shang, Y. Yang, et al. Optimization and Test of Potato stubble cutting Machine [J]. Transactions of the Chinese Society for Agricultural Machinery, 47(05):106-114, (2016).

7. H.Q. Liu. Techniques for mechanized stubble and harvesting of potatoes [J]. Journal of Friends of Farmers, (11):25, (2019).

8. J.Q. Zhang, R.Q. Liang, Z.Q. Dong, et al. Development status of potato stalks and leaf silage and development of silage harvester [J]. Journal of Agricultural Mechanization Research, 41(05):262-268, (2019).

9. X.L. Tang, G.Y. Ren, et al. Summary of the Causes of Potato Harvest Damage in Southwest [J]. China Agricultural Development and Equipment, (09):93-94, (2020).

10. J. Song, Z.Q. Lv, et al, Current Situation and Development of Potato Mechanized Potato stubble Treatment [J]. Farm Machinery, (11):100-103, (2019). 